\title{
Papers
}

\section{Familial, psychiatric, and socioeconomic risk factors for suicide in young people: nested case-control study}

\author{
Esben Agerbo, Merete Nordentoft, Preben Bo Mortensen
}

\begin{abstract}
Objective To estimate the risk of suicide in young people related to family and individual psychiatric and socioeconomic factors.

Design Population based nested case-control study. Setting Data from longitudinal Danish registers. Cases and controls 496 young people aged 10-21 years who had committed suicide during 1981-97 in Denmark and 24800 controls matched for sex, age, and time.

Main outcome measures All suicides in Denmark compared with controls; parents and siblings identified from population based registers; inpatient information from discharge registers of national hospitals; and socioeconomic data from administrative registers.

Results Parental factors associated with an increased risk of suicide in young people were suicide or early death, admission to hospital for a mental illness, unemployment, low income, poor schooling, and divorce, as well as mental illness in siblings and mental illness and short duration of schooling in the young people themselves. The strongest risk factor was mental illness in the young people. The effect of the parents' socioeconomic factors decreased after adjustment for a family history of mental illness and a family history of suicide.

Conclusions Recognising mental illness in young people and dealing with it appropriately could help prevent suicides. The high relative risk associated with a low socioeconomic status of the parents may be confounded and overestimated if not adjusted for mental illness and suicide in the family.
\end{abstract}

\section{Introduction}

In recent years there has been growing concern over suicide in young people, particularly as the rates have increased in several countries. ${ }^{12}$ Young people who commit suicide often have a history of mental illness, a family history of mental illness or suicidal behaviour, or dysfunctional family backgrounds such as divorce or socioeconomic adversity. ${ }^{3-7}$ Yet the link between family related risk factors and their relative importance in suicide in young people is poorly understood because studies have either not included all the factors, using the same methods, or not been population based.
Several countries have developed preventive strategies for suicide, and in some of these countries young people are considered an important target group. ${ }^{8}$ Preventive strategies cannot, however, be based on empirical evidence as this does not exist. ${ }^{9}$ Current knowledge of risk factors for suicide in young people stems from either studies of risk factors in people that have attempted suicide or studies of psychological autopsy (information collected on the deceased through interviews with family members, relatives, friends, and healthcare staff), in which recall bias cannot be excluded. We aimed to determine the effect of familial, psychiatric, and socioeconomic factors in young people who had committed suicide.

\section{Methods}

\section{Sources of data}

We obtained data from Danish population based registers on the basis of the unique identification number assigned to everyone living in Denmark, thus ensuring accurate linkage of information between registers. ${ }^{10} \mathrm{We}$ identified the biological mother, father, and siblingsdefined as people sharing a biological parent-from the Danish civil registration system. ${ }^{10}$ Some data were missing for fathers, as they had not been identified by the mothers when registering their children. We considered people as immigrants who were born after 1960 and who had no reference to a mother. ${ }^{11}$

The Danish medical register on vital statistics contains the dates and causes of all deaths in Denmark since 1976 and for suicides since $1970 .^{12}$ Suicides are defined as ICD-8 (international classification of diseases, 8th revision) codes E950-E959 and ICD-10 codes X60-X84.

The Danish psychiatric central register includes the dates for admission and discharge and diagnoses for all psychiatric inpatients in Denmark since 1969 according to ICD-8 and ICD-10 codes. ${ }^{13}$ No private psychiatric hospitals exist in Denmark, and all treatment is free.

The integrated database for longitudinal labour market research contains detailed yearly information for the Danish population from 1980 onwards, with information from administrative registers. Information was only recorded for people living in the country on 31 December, thus excluding those who had emigrated or died within the year.
National Centre for
Register-based
Research, University
of Aarhus, DK-8000
Aarhus C, Denmark
Esben Agerbo
assistant professor
Preben Bo
Mortensen
professor
Psychiatric
Department E,
Bispebjerg Hospital,
DK-2400
Copenhagen NV,
Denmark
Merete Nordentoft
associate professor
Correspondence to:
E Agerbo
ea@ncrr.dk 


\section{Nested case-control design}

We identified 496 cases of suicide during 1981-97 in young people aged 10-21 years who had a reference to a biological mother and who were living in Denmark the previous year. We matched each person to a representative random subsample of 50 people of the same sex who were born the same year, were alive at the particular age (counted in days) and date, had a reference to a biological mother, and were living in Denmark the previous year. ${ }^{14}$ This yielded 24800 controls.

From the Danish psychiatric central register we added explanatory variables indicating whether the person, at the last admission before the matching date, had been admitted to a psychiatric hospital with schizophrenia (codes 295 (ICD-8), F20 (ICD-10)), affective disorders (codes 296 (ICD-8), F30-F39 (ICD-10)), eating disorders (codes 3065 (ICD-8), F50 (ICD-10)), and other psychiatric diagnoses. Deliberate self harm before and during admission was only recorded for 1989-94.

We linked parents and siblings born before the matching date to the Danish medical register on vital statistics (parental vital status relates to death by suicide or other causes, emigration or (in the case of fathers) being unknown at individual's birth, or living in Denmark) and the Danish psychiatric central register, and we obtained information on suicide and other causes of death and admission status before the particular matching date. We also included alcoholism in parents (codes 291 and 303 (ICD-8), F102 (ICD-10)).

Variables for socioeconomic factors in the parents were marital status, job status, educational attainment, and income. We included these only for parents alive at the matching date and living in Denmark on December 31 the previous year. We grouped educational attainment into university, vocational training, high school, primary school, and unknown.

\section{Statistical analysis}

We used Fisher's Monte Carlo sampled exact test for homogeneity between the two sexes with age among the cases. We analysed data by conditional logistic regression with the PhReg procedures in SAS (version 8.1 ), and we computed relative risks, $95 \%$ confidence intervals, Wald tests, and associated $\mathrm{P}$ values. We tested interactions with age by including dummy variables indexing older (younger) than median age among exposed individuals and by including age in years as a continuous variable for exposed individuals. We calculated the attributable risk after adjustment for other risk factors from the fitted model, and we calculated an asymptotic $95 \%$ confidence interval by using the delta method and variances and covariances from the proportion of exposed individuals and the incidence rate ratios.

Table 1 Age and sex of 110 females and 386 males who committed suicide in Denmark during 1981-97

\begin{tabular}{lccrrrrrrrrr} 
& \multicolumn{10}{c}{ Age (years) } \\
\cline { 2 - 14 } & $\mathbf{1 0}$ & $\mathbf{1 2}$ & $\mathbf{1 3}$ & $\mathbf{1 4}$ & $\mathbf{1 5}$ & $\mathbf{1 6}$ & $\mathbf{1 7}$ & $\mathbf{1 8}$ & $\mathbf{1 9}$ & $\mathbf{2 0}$ & $\mathbf{2 1}$ \\
\hline Female & 0 & 0 & 0 & 2 & 4 & 9 & 15 & 16 & 18 & 29 & 17 \\
\hline Male & 1 & 3 & 6 & 15 & 22 & 16 & 31 & 54 & 69 & 79 & 90 \\
\hline
\end{tabular}

\section{Results}

Overall, 496 young people in Denmark committed suicide during 1981-97 (table 1). Males were three and a half times more likely to commit suicide than were females, and the number of suicides increased homogeneously with age in both sexes.

The risk of suicide was increased among young people with a parental history of suicide, admission for a mental illness, being single, being unemployed (doseresponse association), or being a recipient of social benefits, or whose sibling had been admitted with a mental illness, whose mother had died from other causes or had emigrated, or whose father had a poor education or was in the lowest quarter for income (table 2). Risk factors related to the father's socioeconomic background were stronger than those of the mother's, whereas risk factors related to the mother's vital status and admissions for a mental illness were stronger than those of the father's. In the young people themselves a strong association was found between suicide and admission to hospital for mental illnesses, and an inverse association was found between risk of suicide and education.

The effect of the risk factors decreased after adjustment for a family history of admission for a mental illness (table 2). This decrease was more pronounced for parental socioeconomic factors and less distinct for factors related to parental vital status and psychiatric history, whereas the effect of individual admission for a mental illness remained the main risk factor.

When all factors were considered those for parental suicide or admission for a mental illness or the loss of a mother due to other causes of death or emigration remained significant. No specific psychiatric diagnosis in a parent was associated with a significantly increased risk of suicide in the offspring. The effects of the parents' job status and education were reduced and non-significant. However, the direction of these factors was similar to that of the crude analysis. These changes were primarily due to confounding between these socioeconomic variables and a family history of admission for mental illness, because the incidence rate ratios were similar to those adjusted for admission for mental illness in the family. A history of admission with a mental illness among the young people was relatively unchanged and remained the strongest risk factor. The risk of suicide among those admitted with schizophrenia was significantly higher than that associated with other psychiatric diagnoses, even though young males with other psychiatric diagnoses had a lower risk than young females. Only young females were admitted with affective disorders and eating disorders. The difference between the sexes was also significant among those whose father had been admitted for a mental illness, with only young females having a significantly increased risk. Moreover, individual education remained a protective factor. An interaction with age was only significant in those whose father had been admitted for a mental illness, when the relative risk declined with the subject's age.

The distribution of risk factors and the adjusted relative risk associated with the most significant factors were transformed into attributable risks (table 3). If all individuals had a similar risk to those not exposed to individual mental illness, mental illness in a parent, or 
Table 2 Suicide in relation to individual mental illness and educational level, suicide and admission for mental illness in parent, and socioeconomic status of parents for 496 young people who committed suicide and 24800 controls. Values are incidence rate ratios (95\% confidence intervals) unless stated otherwise

\begin{tabular}{|c|c|c|c|c|}
\hline Risk factor and category & No of cases/controls & Adjusted for age and sex & Adjusted for psychiatric admission in parent ${ }^{\star}$ & Adjusted incidence rate ratio \\
\hline \multicolumn{5}{|l|}{ Father } \\
\hline \multicolumn{5}{|l|}{ Vital status: } \\
\hline Death by suicide & 10/138 & 3.80 (1.99 to 7.26$)$ & 3.03 (1.53 to 5.98$)$ & 2.30 (1.10 to 4.80$)$ \\
\hline Death by other cause & 9/350 & 1.35 (0.69 to 2.63$)$ & $0.80(0.39$ to 1.65$)$ & $0.63(0.29$ to 1.35$)$ \\
\hline Emigrated or unknown at subject's birth & $38 / 1280$ & 1.56 (1.11 to 2.19 ) & 1.36 (0.96 to 1.94$)$ & 1.08 (0.66 to 1.75$)$ \\
\hline Living in Denmark & 439/23032 & 1 & 1 & 1 \\
\hline \multicolumn{5}{|l|}{ Psychiatric history: } \\
\hline Admitted versus not admitted & $54 / 1170$ & 2.46 (1.85 to 3.29 ) & 1.90 (1.39 to 2.57$)$ & 1.56 (1.12 to 2.19$)$ \\
\hline \multicolumn{5}{|l|}{ Marital status: } \\
\hline $\begin{array}{l}\text { Married or cohabitant versus other } \\
\end{array}$ & $334 / 19794$ & 0.52 (0.42 to 0.65$)$ & 0.67 (0.53 to 0.85$)$ & 0.77 (0.58 to 1.03$)$ \\
\hline \multicolumn{5}{|l|}{ Job status: } \\
\hline Fully employed or self employed & $308 / 17835$ & 1 & 1 & 1 \\
\hline \multicolumn{5}{|l|}{ \% employment in year: } \\
\hline $80-99$ & $26 / 1586$ & 0.95 (0.63 to 1.42$)$ & $0.90(0.59$ to 1.36$)$ & 0.85 (0.56 to 1.29$)$ \\
\hline $20-79$ & 40/1619 & $1.43(1.02$ to 2.00$)$ & 1.37 (0.98 to 1.93$)$ & 1.19 (0.82 to 1.72$)$ \\
\hline $0-19$ & $15 / 453$ & 1.92 (1.13 to 3.25$)$ & 1.61 (0.93 to 2.78$)$ & 1.34 (0.74 to 2.41$)$ \\
\hline Recipient of social benefits & $50 / 1539$ & 1.89 (1.39 to 2.55$)$ & 1.35 (0.96 to 1.88$)$ & $1.12(0.76$ to 1.65$)$ \\
\hline \multicolumn{5}{|l|}{ Educational achievement: } \\
\hline University or other of longer duration & $66 / 4349$ & 0.68 (0.51 to 0.90$)$ & 0.71 (0.53 to 0.95$)$ & 0.73 (0.52 to 1.01 ) \\
\hline Vocational training & $159 / 9203$ & 0.77 (0.62 to 0.97$)$ & 0.80 (0.64 to 1.01$)$ & 0.83 (0.66 to 1.05$)$ \\
\hline High school & $7 / 233$ & 1.33 (0.62 to 2.88$)$ & $1.09(0.47$ to 2.50$)$ & $1.13(0.48$ to 2.65$)$ \\
\hline Unknown & $86 / 3380$ & 1.03 (0.75 to 1.42$)$ & 1.01 (0.73 to 1.40$)$ & 0.95 (0.68 to 1.33 ) \\
\hline Primary school & 159/7137 & 1 & 1 & 1 \\
\hline \multicolumn{5}{|l|}{ Income: } \\
\hline Lowest quarter versus other & $129 / 4946$ & 1.52 (1.24 to 1.88$)$ & 1.26 (1.01 to 1.57 ) & 1.04 (0.79 to 1.36$)$ \\
\hline \multicolumn{5}{|l|}{ Mother } \\
\hline \multicolumn{5}{|l|}{ Vital status: } \\
\hline Death by suicide & 9/63 & 7.55 (3.74 to 15.3 ) & 4.77 (2.20 to 10.3$)$ & 4.75 (2.10 to 10.8$)$ \\
\hline Death by other cause & $10 / 212$ & 2.49 (1.31 to 4.75$)$ & 2.05 (1.04 to 4.01$)$ & 2.06 (1.02 to 4.19$)$ \\
\hline Emigrated & $17 / 314$ & 2.86 (1.74 to 4.70 ) & 2.34 (1.38 to 3.97$)$ & 2.09 (1.11 to 3.96$)$ \\
\hline Living in Denmark & $460 / 24211$ & 1 & 1 & 1 \\
\hline \multicolumn{5}{|l|}{ Psychiatric history } \\
\hline Admitted versus not admitted & $75 / 1375$ & 3.06 (2.37 to 3.93 ) & 2.02 (1.53 to 2.66 ) & 1.73 (1.29 to 2.32 ) \\
\hline \multicolumn{5}{|l|}{ Marital status: } \\
\hline Married or cohabitant versus other & $341 / 19800$ & 0.71 (0.58 to 0.88 ) & 0.84 (0.67 to 1.05$)$ & $1.04(0.80$ to 1.37$)$ \\
\hline Job status: & & & & \\
\hline Fully employed or self employed & 280/16386 & 1 & 1 & 1 \\
\hline \% employment in year: & & & & \\
\hline $80-99$ & $32 / 1725$ & 1.08 (0.75 to 1.57$)$ & $1.08(0.75$ to 1.57$)$ & 1.02 (0.70 to 1.49$)$ \\
\hline $20-79$ & 49/2095 & 1.37 (1.01 to 1.86$)$ & $1.22(0.89$ to 1.67$)$ & 1.13 (0.82 to 1.56$)$ \\
\hline $0-19 \%$ & $21 / 715$ & 1.72 (1.10 to 2.69$)$ & 1.51 (0.95 to 2.39$)$ & $1.37(0.85$ to 2.20$)$ \\
\hline Recipient of social benefits & $78 / 3290$ & 1.39 (1.08 to 1.79$)$ & $1.10(0.84$ to 1.45$)$ & 1.05 (0.76 to 1.47$)$ \\
\hline Educational achievement: & & & & \\
\hline University or other of longer duration & $76 / 4258$ & 0.89 (0.68 to 1.17$)$ & 0.96 (0.73 to 1.26$)$ & 1.15 (0.84 to 1.56$)$ \\
\hline Vocational training & 135/7758 & 0.88 (0.70 to 1.09$)$ & 0.98 (0.78 to 1.23$)$ & 1.11 (0.88 to 1.41$)$ \\
\hline High school & $10 / 307$ & $1.63(0.85$ to 3.11$)$ & 1.35 (0.68 to 2.72$)$ & 1.46 (0.72 to 2.98$)$ \\
\hline Unknown & $50 / 1821$ & 1.13 (0.79 to 1.62$)$ & $1.13(0.78$ to 1.63$)$ & $1.10(0.76$ to 1.60$)$ \\
\hline Primary school & 206/10381 & 1 & 1 & 1 \\
\hline Income: & & & & \\
\hline Lowest quarter versus other & $137 / 6349$ & $1.19(0.98$ to 1.46$)$ & $1.04(0.84$ to 1.28$)$ & 0.99 (0.77 to 1.28$)$ \\
\hline Siblings & & & & \\
\hline At least one sibling versus none & 466/23103 & $1.14(0.79$ to 1.66$)$ & $1.17(0.80$ to 1.72$)$ & $1.29(0.87$ to 1.90$)$ \\
\hline Psychiatric history: & & & & \\
\hline Admitted versus other & $27 / 586$ & 2.39 (1.61 to 3.56$)$ & 1.29 (0.83 to 2.01$)$ & 1.21 (0.78 to 1.88$)$ \\
\hline Dead by suicide: & & & & \\
\hline One or more siblings versus none & $1 / 19$ & $2.64(0.35$ to 19.8$)$ & $1.34(0.16$ to 11.6$)$ & $1.40(0.17$ to 11.7$)$ \\
\hline Dead by other cause & & & & \\
\hline One sibling versus none & $7 / 282$ & 1.25 (0.59 to 2.67$)$ & 1.18 (0.54 to 2.56$)$ & $1.13(0.52$ to 2.45$)$ \\
\hline Psychiatric history: & & & & \\
\hline Schizophrenia & $15 / 23$ & 39.5 (20.4 to 76.7 ) & 35.5 (18.0 to 69.7 ) & 33.1 (16.5 to 66.3$)$ \\
\hline Affective disorders & $4 / 8$ & 35.0 (9.97 to 123$)$ & $25.7(7.10$ to 92.9$)$ & 24.3 (6.64 to 88.7 ) \\
\hline Eating disorders & $2 / 1$ & 120 (10.6 to 1356$)$ & $74.2(6.35$ to 865$)$ & 84.9 (7.17 to 1006$)$ \\
\hline Other diagnoses & $57 / 222$ & 15.3 (11.2 to 20.8$)$ & 11.9 (8.61 to 16.5$)$ & $10.8(7.75$ to 15.0$)$ \\
\hline Never admitted & $418 / 24546$ & 1 & 1 & 1 \\
\hline Educational achievement: & & & & \\
\hline High school or other of longer duration & $31 / 2238$ & 0.55 (0.37 to 0.81 ) & $0.66(0.45$ to 0.99$)$ & 0.71 (0.47 to 1.07$)$ \\
\hline Vocational training & $10 / 1480$ & 0.26 (0.14 to 0.49$)$ & 0.35 (0.18 to 0.68$)$ & $0.37(0.19$ to 0.70$)$ \\
\hline Primary school & 455/21082 & 1 & 1 & 1 \\
\hline
\end{tabular}

${ }^{\star}$ Adjusted for age, sex, calendar time, and individual and family history of admission for mental illness. 
Table 3 Percentage attributable risk according to individual and parental history of suicide or admission for mental illness

\begin{tabular}{lc} 
Risk factor & Attributable risk (95\% Cl) \\
\hline Father: & \\
\hline Suicide & $1.1(0.0$ to 2.0$)$ \\
\hline Admission for mental illness & $3.9(1.3$ to 6.4$)$ \\
\hline Mother: & $1.4(0.0$ to 2.4$)$ \\
\hline Suicide & $6.4(3.5$ to 9.3$)$ \\
\hline Admission for mental illness & $15(12$ to 17$)$ \\
\hline Individual admission for mental illness &
\end{tabular}

suicide of a parent, the proportion of suicides that would be prevented was about $30 \%$, of which $15 \%$ was attributed to mental illness in the young person.

\section{Discussion}

Young people are more likely to commit suicide if a parent has died, whether from suicide or other causes, they have a family history of mental illness or unemployment, the parent is single, the mother has emigrated, the father had a poor education, a sibling had been admitted for a mental illness, or the individual had a history of mental illness or limited schooling. The low socioeconomic position of a parent was confounded by aggregation of mental illness and suicide in the family. These findings are robust, as the registers from which information was extracted contain reliable information.

Parental suicide, death, mental illness, and socioeconomic position

Our results from the unadjusted model agree with previous reports of increased risks of suicide associated with aggregation of mental illness, suicidal behaviour, divorce, decreasing levels of employment, and increasing poverty in the family. ${ }^{4-7}$ However, we found that when the results from studies of divorce and socioeconomic status in parents were not adjusted for mental illness and suicide in the family they were likely to be confounded by overestimating the effect of the risk factors. We lacked data for quantifying the effect of exposure to adverse, dysfunctional, or abusive circumstances in the family or during childhood. A further hypothesis, supported by a recent study of suicides in adults, could be that the importance of socioeconomic factors might be different in families with a history of mental illness or suicide. ${ }^{15}$

Studies in twins and adopted children suggest that genetic factors play a part in suicide in families. ${ }^{16}{ }^{17}$ However, it is unknown whether suicide is mediated by mental illness or by specific genes. Our study confirms an increased risk of suicide in the offspring of parents that commit suicide, although the effect of upbringing cannot be separated from genetic factors. This effect could not be explained by a history of admission for a mental illness in the family, and therefore our findings could be explained only by the effect of untreated or under treated mental illness in the family or by genetic factors.

We also found that young people were at a higher risk of committing suicide if their mother had died early, making the link between early death and unmeasured socioeconomic hardship less likely. Young people were also more likely to commit suicide if their mother had emigrated the year before the suicide (matching date) or was living abroad. Although these differences are crude proxies for the parent-child relationship, they do suggest that an impaired relationship and poor attachment and bonding between mother and child are more important than those between father and child. ${ }^{25}$

\section{Untreated, undertreated, and undiagnosed mental illnesses}

We found that $15 \%$ of the young people who had committed suicide had been admitted for a mental illness, which compares to a Finnish study but is lower than in other studies and less than in the adult population..$^{18-21}$ Studies that are based on psychological autopsy, selected populations, or interviews with survivors, carry a risk of overestimating the prevalence of mental illness because of recall bias. The effects of mental illness in our study could be overestimated if those who had the more severe mental illness were also more likely to be admitted to a psychiatric hospital. Otherwise, the effect of mental illness could be underestimated if the distributions of severity were the same among individuals admitted as those not admitted. Thus a limitation of our study is that the results were based solely on histories of inpatient admissions.

The effect of mental illness and suicide in a parent as well as the effect of limited schooling in the young people themselves may partly reflect a deficiency in the diagnosis and treatment of mental illnesses. A substantial proportion of young people who commit suicide may have an untreated, under treated, or undiagnosed mental illness.

The rate of suicide was even greater in females admitted with a mental illness, confirmed by a recent study of suicide in adults. ${ }^{22}$ The most likely explanation for this is that young males, not treated for mental illness had a higher suicide rate than their female counterparts. Furthermore, the rate is strongly linked

\section{What is already known on this topic}

Young people who commit suicide have a history of mental illness or a family history of mental illness or suicidal behaviour

Dysfunctional family backgrounds and socioeconomic adversity also contribute to suicide in young people

Targets for preventive strategies are controversial, as few population based studies have been conducted and none have included all the risk factors

\section{What this study adds}

Suicide is more likely among young people if a parent commits suicide or there is a history of mental illness in the individual and their siblings

Socioeconomic risk factors seem to be less important

Preventive strategies should be aimed at the early recognition and optimal treatment of mental illnesses 
to disorders that are more common among females; in our study all but schizophrenia. ${ }^{23}$

\section{Suicide prevention and clinical implications of the study}

We found that mental illness in young people and a family history of suicide and mental illness were the most important risk factors for suicide among young people. Therefore an important target in the prevention of suicide in young people would be the early recognition and treatment of mental illness. Improved psychopathological assessment and treatment after discharge from psychiatric facilities could therefore help decrease suicide rates. However, as only $30 \%$ of the suicides in our study could be attributed to these factors, preventive measures should be aimed at the general population.

EA contributed to the conception and design of the study, data analyses and management, wrote the drafts and the final paper, and took the lead role in discussions; he will act as guarantor for the paper. $\mathrm{MN}$ and $\mathrm{PBM}$ participated in discussions and contributed to writing and revising the paper.

Funding: The National Centre for Register-based Research was supported by the Danish National Research Foundation. The study was supported by the Theodore and Vada Stanley Foundation and by the Danish Research Council (grant No 9600264).

Competing interests: None declared.

1 Weber W. EU calls for action to prevent youth suicide. Lancet 2000;356:1090.

2 Cantor CH. Suicide in the western world. In: Hawton K, van Heeringen K, eds. The international handbook of suicide and attempted suicide. New York: John Wiley, 2000:9-28.

3 Bell CC, Clark DC. Adolescent suicide. Pediatr Clin North An 1998;45:365-80.

4 Brent DA, Bridge J, Johnson BA, Connolly J. Suicidal behaviour runs in families. Arch Gen Psychiatry 1996;53:1145-52.

5 Gould MS, Fisher P, Parides M, Flory M, Shaffer D. Psychosocial risk factors of child and adolescent completed suicide. Arch Gen Psychiatr 1996;53:1155-62.
6 Gould MS, Shaffer D, Fisher P, Garfinkel R. Separation/divorce and child and adolescent completed suicide. J Am Acad Child Adolesc Psychiatry 1998;37:155-62.

7 Beautrais AL, Joyce PR, Mulder RT. Youth suicide attempts: a social and demographic profile. Aust NZ J Psychiatry 1998;32:349-57.

8 Jenkins R, Singh B. General population strategies of suicide prevention In: Hawton K, van Heeringen K, eds. The international handbook of suicide and attempted suicide. New York: John Wiley, 2000:597-616.

9 Van der Sande R, Buskens E, Allart E, Van der Graaf Y, Van Engeland H. Psychosocial intervention following suicide attempt: a systematic review of treatment interventions. Acta Psychiatr Scand 1997;96:43-50.

10 Malig C. The civil registration system in Denmark. Bethesda, MD International Institute for Vital Registration and Statistics, 1996. Technical paper No 66

11 Knudsen LB. The Danish medical birth registry. Dan Med Bull 1998;45:221-5

12 Danish National Board of Health. Cause of death in Denmark 1990 Copenhagen: Danish National Board of Health, 1992. [In Danish.]

13 Munk-Jørgensen P, Mortensen PB. The Danish psychiatric central register. Dan Med Bull 1997;44:82-4.

14 Clayton D, Hills M. Statistical models in epidemiology. Oxford: Oxford University Press, 1993.

15 Agerbo E, Mortensen PB, Eriksson T, Qin P, Westergård-Nielsen N. Risk of suicide in relation to income level in people admitted to hospital with mental illness: a nested case-control study. BMJ 2001;322:334-5.

16 Roy A, Segal NL, Centerwall BS, Robinette CD. Suicide in twins. Arch Gen Psychiatry 1991;48:29-32.

17 Schulsinger F, Kety SS, Rosenthal D, Wender PH. A family study of suicide. In: Schou M, Strömgren E, eds. Origin, prevention and treatment of affective disorder. London: Academic Press, 1979:277-87.

18 Marttunen MJ, Henriksson MM, Aro HM, Heikkinen ME, Isometsa ET Lonnqvist JK. Suicide among female adolescents: characteristics and comparison with males in the age group 13 to 22 years. J Am Acad Child Adolesc Psychiatry 1995;34:1297-307.

19 Runeson B. Mental disorder in youth suicide. DSM-III-R axes I and II. Acta Psychiatr Scand 1989;79:490-7.

20 Shaffer D, Craft L. Methods of adolescent suicide prevention. J Clin Psychiatry 1999;60(suppl 2):70-4.

21 Mortensen PB, Agerbo E, Eriksson T, Qin P, Westergård-Nielsen N. Psychiatric illness and other risk factors for suicide in Denmark. Lance 2000;355:9-12.

22 Qin P, Agerbo E, Westergård-Nielsen N, Eriksson T, Mortensen PB. Gender differences in risk factors for suicide in Denmark. Br J Psychiatry 2000; $177: 546-50$

23 Hawton K. Gender differences in suicidal behaviour. Br J Psychiatry 2000;177:484-5.

(Accepted 29 January 2002) 